\title{
MEMÓRIA DA LÍNGUA E ENSINO: MODOS DE APARECIMENTO DE UMA LÍNGUA APAGADA NO TRABALHO DO ESQUECIMENTO
}

\author{
Maria Onice Payer
}

RESUMO: L'article expose le fonctionnement actuel de la mémoire de la langue des sujets immigrants, en considérant la réduction au silence de leur langue maternelle dans l'histoire brésilienne. Notre but est de comprendre la relation entre le sujet et la langue, dans la rencontre entre la langue nationale et la langue maternelle. Cette question a trait à la connaissance des processus de subjetivation qui se présentent dans l'enseignement de la (des) langue(s) et également dans la relation plus large de la société avec elle(s), soit par le biais de la mémoire, soit par celui de l'oubli. On y aborde certains aspects de la relation sujet/langue qui se manifestent à travers le rire dans l'énonciation d'une langue réduite au silence; du chanter dans cette langue; à travers la survalorisation des formes considérées comme correctes de la langue nationale, et aussi la dénégation (méconaissance) de la présence d'autres langues dans la mémoire linguistique des locuteurs - quand en fait leurs traces sont présentes dans la pratique langagière. En ce sens, il n'est pas suffisant d'enseigner des langues réduites au silence dans les régions d'immigration, comme il le semble à première vue. On soutient l'importance d'un effectif travail de mémoire dans le sujet, pour la

Maria Onice Payer é professora na Universidade Federal de São Carlos (SP) e na Universidade do Vale do Sapucaí (MG). 
compréhension de la dimension discursive, telle qu'elle se présente dans la situation historique de l'immigration au Brésil.

PALAVRAS-CHAVE: memória da língua, esquecimento, ensino, sujeito.

\section{INTRODUÇÃO}

Pensando sobre discurso, língua e ensino ${ }^{1}$ relativamente ao campo da memória da imigração, tema a que venho me dedicando nos últimos anos, parece oportuno expor algumas considerações sobre o ensino e/ou o envolvimento com a(s) língua(s) na prática discursiva da oralidade. Serão aqui observados certos modos de aparecimento e de funcionamento, na atualidade, de uma língua (italiano) que foi apagada na história brasileira, dada a política de línguas desenvolvida no Brasil2 ${ }^{2}$. Estes aspectos serão focalizados na sua relação com o sujeito de linguagem.

Um interesse deste estudo é procurar conhecer um pouco mais sobre os processos de significação presentes para os sujeitos a quem se ensina língua, e contribuir deste modo para a compreensão de nossa própria relação com a língua, dada a nossa história como sociedade.

São considerados nesta reflexão alguns elementos de uma pesquisa anterior, realizada no doutorado, em que estudamos processos discursivos relacionados ao campo da imigração italiana (do período republicano), processos através dos quais os imigrantes estrangeiros se transformaram em sujeitos brasileiros.

Em relação à língua, considerando as noções de forma material da língua, e de apagamento e de silenciamento tal como têm sido trabalhadas por E. Orlandi (1992, 1996), estudamos o processo histórico de apagamento da língua dos imigrantes. Processo que se desenrola até a atualidade, quando ainda se encontram traços do italiano, como língua historicamente apagada, na prática oral de linguagem.

Trabalhando na perspectiva do discurso, consideramos esses traços lingüísticos não como "regionalismos", nem como parte de um "extrato sociolingüístico", mas como traços da memória discursiva, e, especifi-

${ }^{1}$ Tema da sessão de trabalho do Encontro Nacional da ANPOLL (Gramado, 2002) em que foi apresentado este trabalho.

${ }^{2}$ Ver a obra História das idéias lingüísticas. Construção do saber metalingüístico e constituição da língua nacional, organizada pela profa. Eni P. Orlandi, resultante do projeto de mesmo nome. 
camente, traços de memória da língua apagada presentes na língua que se pratica cotidianamente nas regiões que tiveram altos índices de imigração.

\section{ESTATUTO DA LÍNGUA HISTORICAMENTE APAGADA NO SUJEI-} TO

Um ponto central que se apresentou como uma questão a partir do estudo da língua em tal situação de imigração, e que procuramos esclarecer um pouco mais neste texto, diz respeito ao fato de que esses traços de memória da língua apagada parecem ter um estatuto constitutivo no sujeito de linguagem: sendo constitutivos, nem sempre eles são representados pelo sujeito que os fala, como traços de uma língua outra. Funcionam antes como evidências da língua para os sujeitos falantes. Na história de imigração, em que mais de uma língua esteve presente - e este seria também o caso de diversos outros grupos sociais e de outras experiências - o sujeito falante seria constituído não só pelo Português, mas também pela língua "apagada", ou por elementos dela, de tal modo que esta última funciona ainda discursivamente, na atualidade, em sua forma de língua apagada mesmo.

Se isto é assim, podemos considerar que a língua apagada ocupa um lugar no sujeito. Nesse lugar, de modo estranhamente palpável e difuso, essa língua comparece, no interior mesmo de seu processo de desaparecimento histórico e de seu esquecimento pelo sujeito. Conforme entendo, este lugar não se deixaria preencher, portanto, como se poderia imaginar, pelo mito do restabelecimento de uma língua perdida. Trata-se de um $l u$ gar de língua, modo de presença que funciona nas formas próprias do trabalho simbólico do esquecimento.

Mas o quê, mais propriamente, haveria nesse lugar de língua?

Como funciona uma língua "apagada" de modo que ainda atualmente traços lingüísticos seus venham se instalar no Português, se não há mais transmissão direta dessa língua sob a forma de ensino? Como se dá, pela via da oralidade ${ }^{3}$, a permanência movediça de um lugar para essa língua no sujeito e em seu discurso?

Revendo com estas preocupações o material da pesquisa de campo recolhido, e relembrando as situações (gravações transcritas de entrevistas e diversas situações de conversas cotidianas com e entre a população (ES)) - anotamos alguns fatos e situações que podem ajudar a pensar essas questões:

${ }^{3}$ No artigo "A Produção Histórica da Oralidade", apresento uma síntese das fontes deste modo de trabalhar com a questão da língua e da oralidade. 
- Diz-se de uma língua que ela não é falada, mas que é escutada; que não é falada, mas é cantada;

- Há situações de enunciação na língua italiana que se dão junto com o riso por parte dos interlocutores.

- Há situações de supervalorização da língua portuguesa em sua forma considerada padrão.

- Há situações de denegação da presença da língua outra.

Certamente haveria outros fatos e situações, mas nesse momento vamos nos limitar ao exame destes acima mencionados.

\section{A escuta e o canto da língua apagada}

No corpus da pesquisa há muitas referências a uma língua que não é falada mas que era ouvida. Pode-se sintetizar estas referências na recorrência do enunciado: eu não falo essa língua, mas na infância escutava (alguém) falar. Há também diversas situações em que a língua que se diz não ser falada (italiano), aparece cantada pelos sujeitos que "não a falam".

Que imigrantes cantem suas canções em dialetos é algo muito notado, e nem retomaríamos este fato senão para trazer à tona algo sobre o modo particular de se "estar" em uma dada língua através da música. Ou seja, queremos chamar a atenção para a diferença entre falar uma língua e cantar nessa mesma língua.

Cantar pode ser considerado uma maneira sinestésica de estar na língua, um envolvimento corpóreo com ela, o que é diferente do ato de falar tal língua.

Considerando a situação em que há uma necessidade histórica do sujeito esquecer uma língua (não falar essa língua), e considerando também que esse tipo de prática de canto ocorre sempre coletivamente, esta situação produz o efeito de que são abertos parênteses no exercício do esquecimento, para, em um evento circunscrito, e coletivamente, o sujeito entregar-se de todo a um embalo no seio da língua. Para depois retornar ao silêncio.

Já o fato de que a língua não seja falada mas tenha sido ouvida indica uma forma de presença opacificada, diluída. Sua memória é difusa. Seu lugar no sujeito é remoto. Sua matéria é esgarçada. R. Robin (1993) fala do escutado, do fônico da língua dos antepassados para o sujeito como "um conhecimento no sentido próprio do termo 'ouvir-dizer', isto é, um desconhecimento muito específico da língua".

Querer acercar-se, pois, de uma presença inteiramente positiva dessa língua impediria notar-se seu modo vago de funcionamento, como 
memória esvaecida mesmo, em uma situação em que se vai exercendo historicamente o esquecimento.

\section{Língua interditada, riso e equívoco}

São freqüentes as situações cotidianas em que enunciados em italiano são seguidos de riso por parte dos interlocutores.

Há nuances dessa situação. A repetição da língua se dá às vezes de modo proposital, com um certo tom de imitação, de estereótipo. E outras vezes há uma irrupção genuína da língua italiana, de modo absolutamente involuntário. Há certas narrativas de situações cômicas em que a enunciação na língua considerada ilegítima constitui por si mesma o efeito cômico.

De que se ri nessa situação? Por que se ri?

A situação lembra aquela um pouco diferente analisada por E. Orlandi (1996), da paródia da língua, na sátira escrita por Juó Bananere em referência ao "português macarrônico", como é conhecido em São Paulo o falar do imigrante italiano. A autora observa que na situação contraditória da mistura de línguas pelo imigrante, "a paródia é sobretudo uma paródia da língua e a questão da pátria é uma questão da relação entre línguas diferentes". E que "essa diferença é trabalhada como sátira" (p. 125). Orlandi diz então que a sátira trabalha o equívoco, a falha, pela contradição e sobrecarga da mistura de línguas.

Na situação de que tratamos, em que o riso que se dá diretamente sobre enunciados falados em italiano, parece não haver trabalho de elaboração da diferença, como na sátira. $\mathrm{O}$ riso aparece em seu estado bruto, na forma da gargalhada, como manifestação corporal de sentidos, como um elemento estranho à língua propriamente dita.

Para compreender o cômico nesta forma de manifestação corporal, nos valemos do texto de Bergson $O$ riso: ensaio sobre a significação da comicidade (2001). O autor diz que o riso depende de uma insensibilidade, que se dá pela possibilidade da suspensão do sentido normal e sério dos acontecimentos. Aponta também outro aspecto: o fato de que se ri em grupo, o que indica que a significação que provoca o riso atinge o senso de coletividade, pois "toca as mesmas cordas" nos indivíduos. O riso produzido pelo cômico, diz o autor, se dá diante de uma mudança involuntária, quando algo escapa ao normal esperado, quando essa mudança involuntária é provocada por um efeito de "rigidez mecânica", de automatismo.

Podemos interpretar a situação de riso que se segue aos enunciados em dialetos italianos então como uma situação de manifestação bruta de um equívoco, no sentido de que fala Authier (1998), de manifestação 
não costurada da presença de um outro no dizer do sujeito. Ri-se do fato de que escapa na fala, como por automatismo, uma língua outra, que não caberia falar. Ri-se de um sujeito que falha deste jeito em seu modo de se exercer na língua. Os sujeitos parecem rir então do outro e de si mesmos, em cumplicidade, por um efeito de inadaptação exposta, em torno da qual há, entretanto, uma conivência. Na tensão, diz Bergson, "o riso flexibiliza o que pode restar de rigidez mecânica na superfície do corpo social".

\section{Supervalorizar ou denegar a língua apagada?}

Observam-se casos de supervalorização da língua portuguesa, no contexto em questão de sujeitos que passaram pela história da imigração. Há indivíduos, filhos de pais que falam uma língua repleta de traços de dialeto, que supervalorizam as formas do português padrão. Falam do modo mais correto possível. Paradoxalmente, isso produz, entretanto, em tais condições específicas, o efeito de ausência de um fluir espontâneo da linguagem. Parece tratar-se de uma vigilância a qualquer vestígio da língua apagada. Essa situação significa de tal modo que atrai muitas vezes a ironia dos que praticam a língua de outra forma, com traços de italiano.

Esta situação se aproxima, por um outro caminho, do quarto aspecto mencionado: há afirmações de que não se aprendeu a língua (apagada), quando de fato se pode notar sua presença funcionando na prática discursiva, de uma forma ou de outra. Parece tratar-se de um processo de denegação da língua outra presente/apagada.

$\mathrm{O}$ enunciado de base encontrado no corpus que representa bem a situação seria: "eu não sei falar a língua $X$, não aprendi. O fulano é que sabe". Mas se falamos com o fulano sobre quem foi dito ter aprendido a língua, este repete o mesmo enunciado: o outro é que sabe, e assim sucessivamente.

São formas variadas pelas quais se exerce o esquecimento necessário da língua historicamente apagada, e que, apagada mesmo, deixa, entretanto, os seus vestígios na forma material da língua (ORLANDI, 1996) e um lugar no sujeito do discurso a trabalhar de um modo subterrâneo.

\section{Um mito: o resgate da língua perdida}

Antes de encerrar provisoriamente essa reflexão, gostaria de alertar sobre alguns riscos encontrados no trabalho sobre uma situação como esta de línguas desaparecidas. Trata-se da facilidade de se desviar da questão de fato para embarcar no mito de resgate da língua perdida, de uma língua da infância ou da origem. J. Authier (1998) observa que esse mito teria 
uma função compensadora, na medida em que busca repor uma perda do real, que é própria a toda língua. Concordamos que não se trata, de fato, de percorrer os caminhos ilusórios de reconstituição de línguas perdidas na história, sem considerar os contextos específicos.

O que consideramos importante atingir, com esse tema, é a especificidade das situações históricas em que se dão conflitos efetivos entre línguas, como no caso da imigração, e a compreensão do quê joga nessas situações, pela relação necessária com a língua nacional ${ }^{4}$, já que esses conflitos recaem de modos específicos e diversos sobre os sujeitos que falam as línguas, e a quem ensinamos língua.

\section{Trabalho do esquecimento e memória da língua}

De nossa parte, propomos trabalhar não exatamente com a língua empiricamente desaparecida, mas sobretudo com a memória dessa língua, de suas relações com outras, de seus sentidos, em suas formas de aparecimento no esquecimento. Se tais situações se relacionam à perda do real pela língua, comum a todos, sua compreensão não precisa, entretanto, parar aí, podendose desvelar outros aspectos do que joga nessas situações, inclusive do mito do resgate da língua como um efeito interno a essas situações históricas.

Haverá que se observar, nesse sentido, algo de específico na relação de sujeitos que passam pela história dos embates explícitos entre línguas, quanto a sua própria relação com a língua de um modo mais geral, e consequientemente em sua relação com o outro e com o mundo. A percepção da presença das diversas línguas, com suas memórias próprias, e o esmaecimento do real que esta situação cava parecem ter significação bastante para instaurar algo no sujeito em sua relação com a língua.

Retornando ao que foi proposto inicialmente, uma reflexão sobre os modos de aparecimento da língua apagada na história, junto ao processo do seu esquecimento, pode interessar na medida em que contribui para pensar os processos de significação presentes aos sujeitos com quem se trabalha sobre a língua, e também sobre o próprio modo de se compreender e trabalhar discursivamente com os processos de sentidos ligados à língua.

Relações especiais com as línguas, em seus sentidos nem sempre representados, às vezes obscuros, atuando de um modo subterrâneo, no esquecimento, jogam certamente o seu papel na aprendizagem da língua e das línguas, bem como na própria constituição do sujeito de linguagem.

\footnotetext{
${ }^{4}$ Desde Pêcheux e Gadet (1981); Orlandi (2001) entre outros, a questão da língua nacional apresenta-se como um ponto crucial a ser considerado no tratamento da heterogeneidade lingüística. Em Payer (1999) encontra-se uma abordagem da relação entre a língua nacional e a língua materna na situação de imigração.
} 


\section{BIBLIOGRAFIA}

AUTHIER, J. Palavras incertas. As não-coincidências do dizer. Campinas, Ed. UNICAMP, 1998.

BERGSON, H. O Riso. Ensaios sobre a significação da comicidade. São Paulo, Martins Fontes, 2001.

ORLANDI, E. Paródia da Língua. O Teatro da Identidade. In: Interpretação. Petrópolis, Vozes, 1996.

_. A Língua Brasileira. In: Língua e conhecimento lingüístico. Campinas, Pontes, 1992.

- (org.) História das Idéias Lingüísticas. Construção do saber metalingüístico e constituição da língua nacional. Campinas, Pontes, Cáceres, Ed. Unemat, 2001.

. As formas do silêncio. Campinas, Ed. da Unicamp, 1992.

PAYER, M.O. Memória da língua. Imigração e Nacionalidade. Tese de Doutorado, IEL, UNICAMP, 1999.

- A Produção Histórica da Oralidade. Boletim Eletrônico do GT de Análise de Discurso da ANPOLL, n.2, set. 2001. www:geocities.com/ gt_ad.

- Memória(s) da Língua. Língua Nacional e Língua materna. Anais da III Conferência Internacional BR 2000. UNICAMP, USP, PUC/SP, Campinas, 16 a 20 de julho de 2000.

PÊCHEUX, M. \& Gadet, F. La langue introuvable. Paris, Maspero, 1981.

ROBIN, R. En deuil de l'origine. Presses Universitaires de Vincennes, 1993. 